\title{
Simulation Analysis of Run Vibration on Vehicle-mounted Optics Image Stabilization System
}

\author{
Dongwei $\mathrm{Li}^{1,2, a}$, Huiyan Chen ${ }^{1, b}$, Guoquan $\operatorname{Ren}^{2, \mathrm{c}}$, and Jun $\mathrm{Han}^{2, \mathrm{~d}}$ \\ 1Beijing Institute of Technology, Beijing 100081,China; \\ 2Mechanical Engineering College, Shijiazhuang 050003,China. \\ a12ldw@163.com, bchen_h_y@263.net,c709955574@qq.com,dhanjun_wy@163.com
}

\begin{abstract}
Keywords: run vibration, optics image stabilization system, ADAMS Simulation, Dynamics Model, vehicle-mounted
\end{abstract}

\begin{abstract}
Vibration, especially at the circumstances of accidental falling down, always cause great damage to vehicle-mounted optics image stabilization system. Therefore, during the process of designing vehicle-mounted optics image stabilization system we need to consider how to reduce the harmful influence of external forces. The paper sets up a simplified second order vibration system and a dynamic model in the ADAMS. We make different simulation analysis on different heights of tank crash. Paper studies the change rule of the angular displacement, angular velocity, angular acceleration and contact force of reflector when it suffers different impact force. The study provides an effective research means for vibration analysis of photoelectric equipment. Results show that angle in pitch changes greater than that in azimuth, which not only provides an important reference for the designer, but also improves the vehicle-mounted optics image stabilization system's environmental adaptability.
\end{abstract}

\section{Introduction}

Vehicle-mounted optics image stabilization system belongs to precise photoelectric equipment, when it works in battle vibration impact do great damage to it. Sometimes, it may breakdown. In order to find the influence of mechanical vibration on vehicle-mounted optics image stabilization system's performance, many researchers use the experimental methods [1]. However, test operation is very difficult; the cycle is long, with heavy workload and high cost. It is hard to complete dynamic response of vibration impact [2]. H. Wang studied the falling response of LCD panel. He also analyzed the change of acceleration and displacement during drop, along with damping and the spring constant. Results provided a theory basis for optimizing structure design and enhanced reliability [3]. Q. Li used mathematical tools to express imaging rule of optical components, results shown that the tiny optical variation will directly affect the firing accuracy, and then lower the work effectiveness [4]. C.Z. Wang analyzed the model of gun control system in the tank fire simulator, got the second order difference equation model of control system [5]. Y.H. Zhang made simulation on a type of infrared lens, extract curve trend of stress, provided an effective research means for infrared product structure design [6]. Numerous researches on the photoelectric device are conducted from theoretical analysis to mathematical modeling and simulation analysis. However, dynamics simulation of the photoelectric structure is uncommon. So it is necessary to make dynamic simulation on the vehicle-mounted optics image stabilization system.

Aiming at the black field phenomenon of tank drop, we use method of computer simulation to study the vibration and shock on the aiming mirror. Firstly, we use ADAMS to make simulation

analysis about a certain type of vehicle-mounted optics image stabilization system during drop, it can forecast damage of aiming mirror when tank drop. As a result, paper put forward an effective means to design optoelectronic device structure. Otherwise, we propose some suggestions to improve the structure adaptability to complex environment. 


\section{Kinematical Model of Vehicle-mounted optics image stabilization system}

\subsection{Simplified Model of Vehicle-mounted optics image stabilization system.}

As shown in Fig.1, the vehicle-mounted optics image stabilization system is installed on top of the turret, mainly including protective mirror, reflector, objective group, reflecting prism and eyepiece. They connect each other through rigid frame and elastic gasket. The control system consists of torque motor, liquid floated gyroscope, as well as mechanical structure and sensitive components of electronic.

When tank accidentally falls down, the impact force will pass through the body part to the top of turret armor, sight base and sights support then finally reaches the primary mirror. Primary mirror, stents, and the outer frame are connected by rigid material body and elastic gasket, it can be considered as a model of mass, spring and damp [7]. The simplified vibration model of the system is shown in Fig.2.

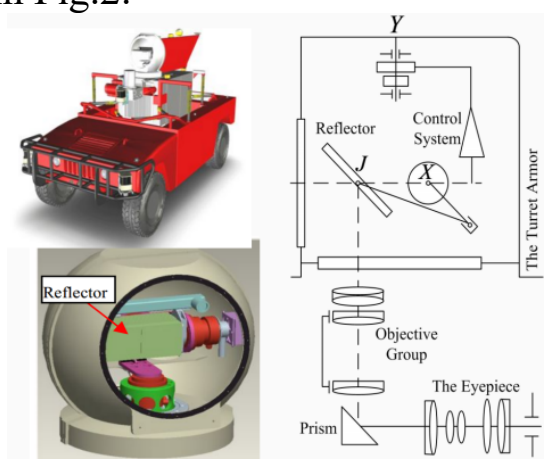

Fig.1 Simple sketch of vehicle-mounted optics image stabilization system(left is the structure picture, right is the theory block)

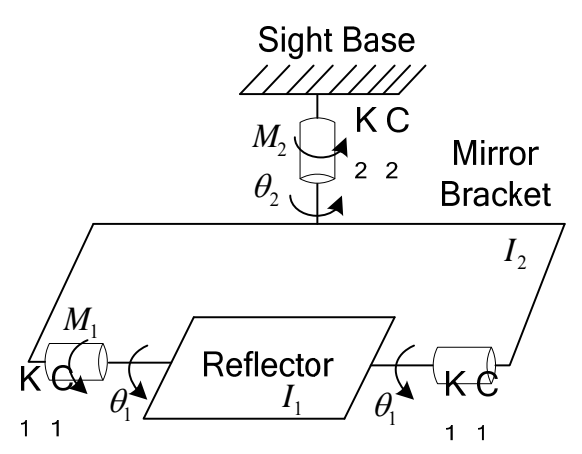

Fig.2 Vibration model of the system

When the tank accidentally fall down, the impact load pass through the body, turret system and reflex stable aiming system. To facilitate the simulation analysis, we make some assumptions about the model.(1) Once tank hits the ground, the vehicle does not rebound, so the movement of sight base and lens rebound can be ignored; (2) The primary mirror is regarded as a rigid body, the system simplified as a free second order vibration system, the falling force passed to the primary mirror by elastic support; (3) Sight bracket using linear elastic material, so that the whole system can be described by a set of mass, spring and damp[8].

\subsection{Kinematics Equation of Reflector.}

Simplified kinematics equation of float type integrating gyroscope can be expressed as

$$
\begin{gathered}
J_{B} \ddot{\beta}+C_{B} \dot{\beta}=H_{G} \omega_{X}+M_{\text {By }} \\
u=k_{\mu} \beta
\end{gathered}
$$

Where

$M_{B y}$ - Control torque, $M_{B y}=k_{M} I_{B y}$;

$I_{B y}$ - Input current of torque motor;

$k_{M}$ - Transfer coefficient of torque motor;

$u$ - Output voltage of angle converter;

$k_{\mu}$ - Transfer coefficient of angle converter.

The input signal is angular velocity $\omega_{X}$, output signal is the voltage $u$ of angle converter, transfer function of the whole system is written as

$$
\frac{\mu(S)}{\omega_{x}(s)}=\frac{H_{G} k_{\mu}}{C_{B}} \frac{1}{S\left(\tau_{G} S+1\right)}
$$


Where $\mu$ is the output voltage of the system, which is the integration of speed; Static transfer function is expressed as $\frac{H_{G} k_{\mu}}{C_{B}}$; Dynamic character of first order system, its time constant is $\tau_{G}=\frac{J_{B}}{C_{B}}$.

Block diagram of float type integral gyroscope is shown in Fig.3. It can be seen from the diagram that $\omega_{X}$ is the input, $\mu$ is the output. This open system consists of integral gyroscope and angle converter [9]. When the system is stable, $\beta$ is the angular of internal frame rolling around the axle, which is the integral of $\omega_{X}$, and the output voltage $\mu$ is proportional of $\beta$.

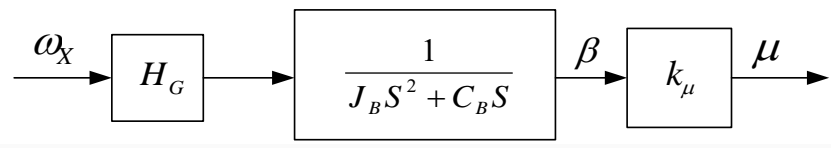

\subsection{Theoretical Basis.}

Fig. 3 Block diagram of float type integral gyroscope

Transient response of reflector can be obtained by solving the kinematics equation. From the vibration model in Fig.2, kinematics equation of the system can be calculated as

$$
\left[\begin{array}{cc}
I_{1} & 0 \\
0 & I_{2}
\end{array}\right]\left[\begin{array}{l}
\ddot{\theta}_{1}(t) \\
\ddot{\theta}_{2}(t)
\end{array}\right]+\left[\begin{array}{cc}
K_{1}+K_{2} & -K_{2} \\
-K_{2} & K_{2}
\end{array}\right]\left[\begin{array}{l}
\theta_{1}(t) \\
\theta_{2}(t)
\end{array}\right]=\left[\begin{array}{l}
M_{1} \\
M_{2}
\end{array}\right]
$$

Where $I_{1}$ and $I_{2}$ are the rotary inertia of reflector and bracket body, $K_{1}$ and $K_{2}$ are the spring stiffness coefficient, $\theta_{1}$ and $\theta_{2}$ are the slant and azimuth angle, $M_{1}$ and $M_{2}$ are the slant and azimuth torque[10].

The equation (4) can be rewritten as

$$
\begin{gathered}
I^{*} \ddot{\Theta}+K^{*} \Theta=M^{*} \\
I^{*}=\left[\begin{array}{cc}
I_{1} & 0 \\
0 & I_{2}
\end{array}\right] \\
K^{*}=\left[\begin{array}{cc}
K_{1}+K_{2} & -K_{2} \\
-K_{2} & K_{2}
\end{array}\right] \\
M^{*}=\left[\begin{array}{l}
M_{1} \\
M_{2}
\end{array}\right]
\end{gathered}
$$

Regardless of the external force, the homogeneous equation can be expressed as

$$
I^{*} \ddot{\Theta}+K^{*} \Theta=0
$$

Where $I^{*}$ and $K^{*}$ are inertia matrix and stiffness matrix respectively, constant matrix composed of coefficient matrix $I^{*}$ and $K^{*}, \Theta$ is a vector about angular displacement, assuming that

$$
K_{1}+K_{2}=K_{11},-K_{2}=K_{12}=K_{21}, K_{2}=K_{22}
$$

Those are the elements of the stiffness matrix $K^{*}$ respectively.

Thus equation (9) can be written as

$$
\left\{\begin{array}{l}
I_{1} \ddot{\theta}_{1}+K_{11} \theta_{1}+K_{12} \theta_{2}=0 \\
I_{2} \ddot{\theta}_{2}+K_{21} \theta_{1}+K_{22} \theta_{2}=0
\end{array}\right.
$$

It's the differential equation of unconstrained system. Where $f(t)$ depend on time section of $\theta_{1}$ and $\theta_{2}$, the solution can be written as

$$
\theta_{1}=\mu_{1} f(t), \theta_{2}=\mu_{2} f(t)
$$

Where $\mu_{1}$ and $\mu_{2}$ signify amplitude. Take the equation (11) into equation (10) 


$$
\left\{\begin{array}{l}
I_{1} \mu_{1} \ddot{f}(t)+\left(K_{11} \mu_{1}+K_{12} \mu_{2}\right) f(t)=0 \\
I_{2} \mu_{2} \ddot{f}(t)+\left(K_{21} \mu_{1}+K_{22} \mu_{2}\right) f(t)=0
\end{array}\right.
$$

In order to make the equation (12) has a solution, there must be

$$
-\frac{\ddot{f}(t)}{f(t)}=\frac{K_{11} \mu_{1}+K_{12} \mu_{2}}{I_{1} \mu_{1}}=\frac{K_{21} \mu_{1}+K_{22} \mu_{2}}{I_{2} \mu_{2}}=\lambda
$$

Because $I_{1}, I_{2}, K_{11}, K_{12}, K_{21}, K_{22}, \mu_{1}$ and $\mu_{2}$ are all real constant, so $\lambda$ must be a real constant. From equation (13)

$$
\ddot{f}(t)+\lambda f(t)=0
$$

If equation (14) has vibration solution, there must be a positive number. If synchronous movement is possible, then harmonic function depend on time. That is to say the only possible solutions is

$$
f(t)=C \sin (\omega t+\varphi)
$$

Where $C$ is a random constant, $\omega$ is the frequency of harmonic vibration, $\omega=\sqrt{\lambda}$ and $\varphi$ is the initial phase angle. All these variable are the same for angle $\theta_{1}$ and $\theta_{2}, C$ and $\varphi$ are determined by the initial conditions.

Calculating equation (11) and (15), then corresponding kinematics equation expressed as

$$
\left\{\begin{array}{l}
\theta^{(1)}(t)=\left[\begin{array}{l}
\theta_{1}^{(1)}(t) \\
\theta_{2}^{(1)}(t)
\end{array}\right]=\mu^{(1)} f_{1}(t)=C_{1}\left[\begin{array}{l}
1 \\
r_{1}
\end{array}\right] \sin \left(\omega_{1} t+\varphi_{1}\right) \\
\theta^{(2)}(t)=\left[\begin{array}{l}
\theta_{1}^{(2)}(t) \\
\theta_{2}^{(2)}(t)
\end{array}\right]=\mu^{(2)} f_{2}(t)=C_{2}\left[\begin{array}{l}
1 \\
r_{2}
\end{array}\right] \sin \left(\omega_{2} t+\varphi_{2}\right)
\end{array}\right.
$$

Where $\mu_{1}^{(1)}$ and $\mu_{1}^{(2)}$ are already taken in $C_{1}$ and $C_{2}$ respectively, $f_{1}(t)$ and $f_{2}(t)$ depend on time, $\omega_{1}, \mu^{(1)}, \omega_{2}, \mu^{(2)}$ correspond to two kinds of synchronous movement. Equation (16) shows two natural orders vibration mode of two degree of freedom system. In general, movement of vibration system usually added by two inherent vibration models, which can be expressed as

$$
\theta(t)=\theta^{1}(t)+\theta^{2}(t)=C_{1}\left[\begin{array}{l}
1 \\
r_{1}
\end{array}\right] \sin \left(\omega_{1} t+\varphi_{1}\right)+C_{2}\left[\begin{array}{l}
1 \\
r_{2}
\end{array}\right] \sin \left(\omega_{2} t+\varphi_{2}\right)
$$

Where constant $C_{1}$ and $C_{2}$, phase angle $\varphi_{1}$ and $\varphi_{2}$ are determined by the initial conditions.

\section{Simulations}

ADAMS Full Simulation Package is a powerful modeling and simulating environment that lets you build, simulate, refine, and ultimately optimize any mechanical system. This paper uses the ADAMS/Post Processor interface to simulate, review, and refine the model [11].

\subsection{Build Kinematic Model.}

Firstly, we establish a simplified model of mirror by UG NX 6.0, and then save the file as another format, finally export the UG model into ADAMS by data exchange interface.

Because the reflector and framework materials are of high intensity and stiffness, they can be regarded as rigid body collides to common ground. Model of the system is shown in Fig.4. Clearance contact is defined between mirror and inner framework, setting a hinge on the reflector. The reflector mass is $1.574 \mathrm{~kg}$, and bracket is $1.796 \mathrm{~kg}$. Inner framework and outer framework is also connected through hinge, and the inner framework can rotate in the direction. In order to simulate movement of reflector in actual equipment better, it is necessary to set a spring on the mirror to recover. 


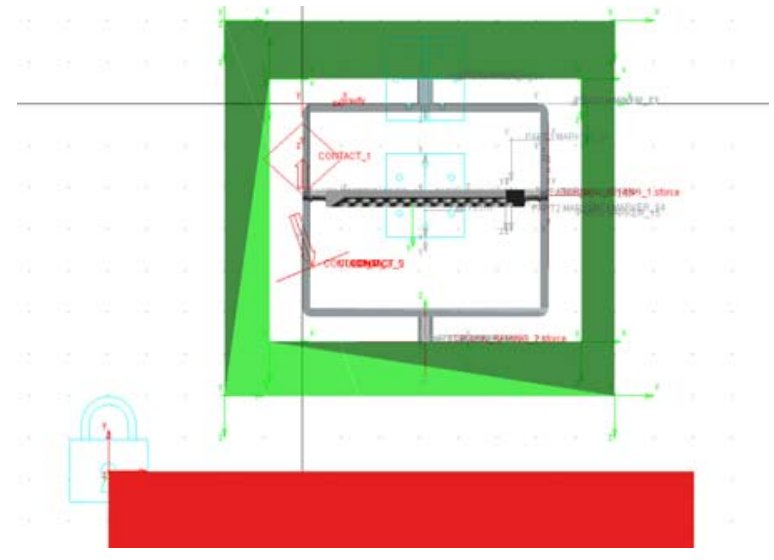

Fig.4 Vibration model of sights

The paper uses the following method to simulate tank crash. Assume that the tank drops from the height of $10 \mathrm{~cm}, 20 \mathrm{~cm}, 30 \mathrm{~cm}$ and $40 \mathrm{~cm}$.

\subsection{Simulation Analysis.}

Because the process of falling down lasts only a moment and the damage happens rapidly. The analysis only focuses on instant response, including angular displacement, angular velocity, angular acceleration and the contact force.

As shown in Fig.5, the tank drop leads to angular skewing in azimuth. The initial angle is $90^{\circ}$, with the increase of drop height, the maximum azimuth alteration also increases, and it can get back to the original position in the end.

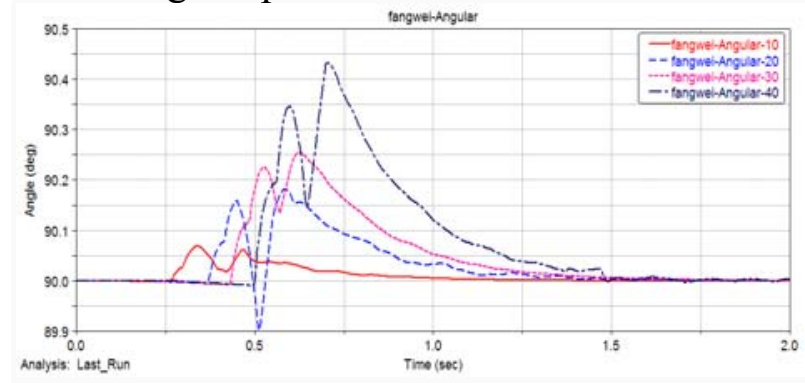

Fig.5 Azimuth angle of reflector

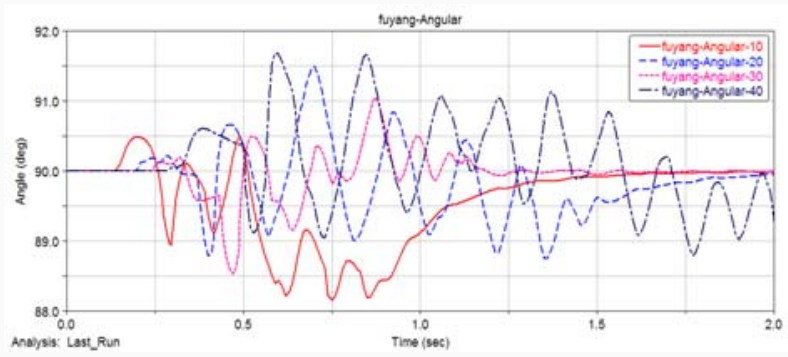

Fig. 6 Pitch angle of reflector

Fig.6 shows the pitch angle changes with time, four different curves are shown about drop heights. When the height between $10 \mathrm{~cm}$ to $30 \mathrm{~cm}$, the mirror can return to the original location within $2 \mathrm{~s}$ after drop, however, when the drop height increases to $40 \mathrm{~cm}$, it recovers for a long time. In addition, angle increases with the increase of drop height, and the influence on pitch angle is bigger than that on the azimuth. It completely shows that the tank crash does greater pitch angle alteration, which provides the focus for future research.

Reflector's pitch angle velocity is shown in Fig.7; from the results we can see that different heights can produce different responses. When the height is less than $30 \mathrm{~cm}$, it is obviously that the maximum pitch angle velocity increases with the increase of drop height. But when the drop height reaches to $40 \mathrm{~cm}$, recover is a time consuming thing. So we should strengthen the pitching control on reflector.

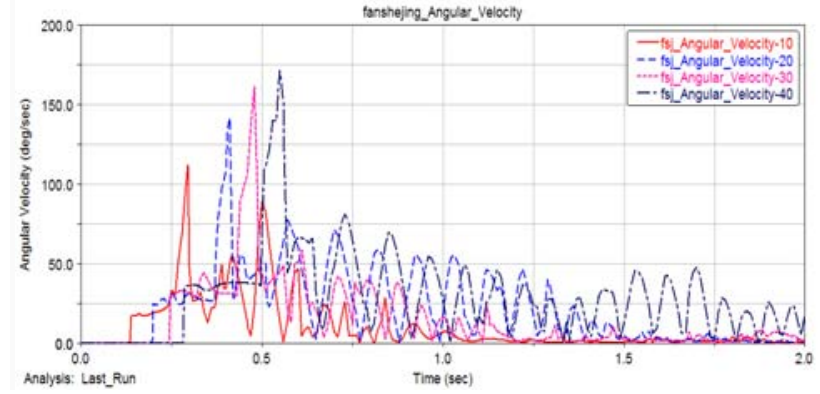

Fig.7 Pitch angle velocity of reflector

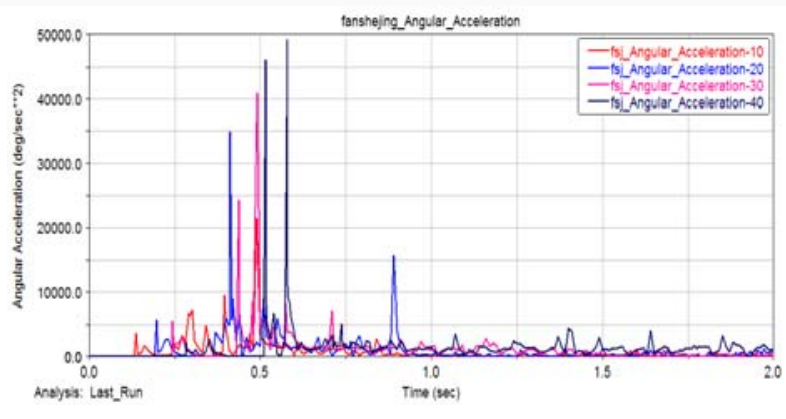

Fig.8 Pitch angle acceleration of reflector 
Angular acceleration response is shown in Fig.8; it reaches the peak at about $0.5 \mathrm{~s}$, and then drops down quickly. Similarly, the peak value increases with the increase of drop height.

As shown in Fig.9, when drop height is less than $30 \mathrm{~cm}$, the velocity of mirror reaches to peak in minute and then reduces to zero rapidly. However, when the drop height increased to $40 \mathrm{~cm}$, it is difficult to restore. Moreover, it's obviously that the peak increases with the increase of drop height.

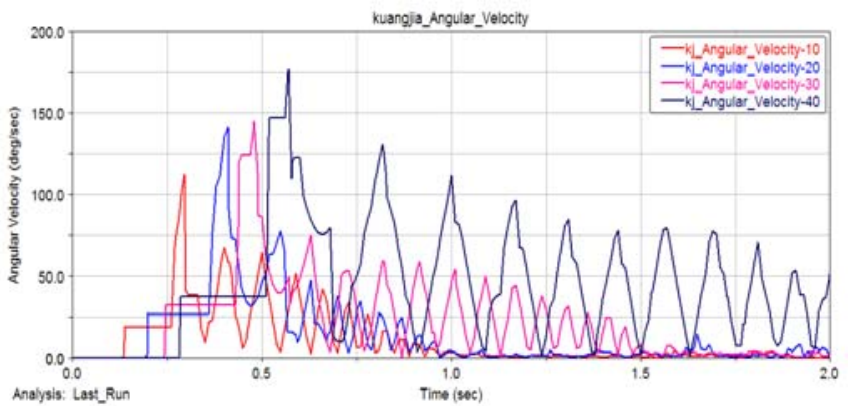

Fig.9 Azimuth angle velocity of reflector

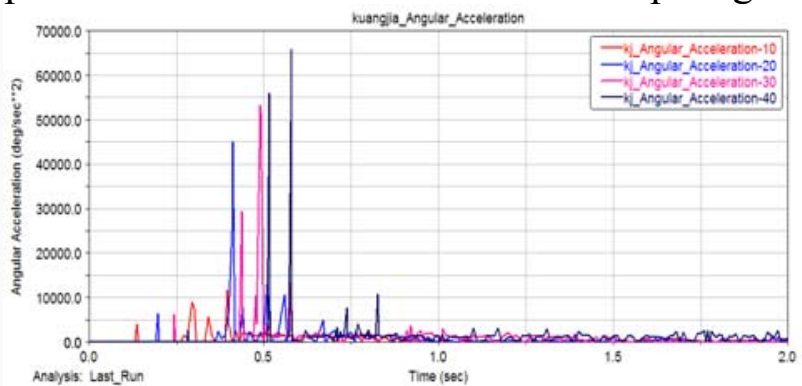

Fig.10 Azimuth angle acceleration of reflector

Similar to the result above, as shown in Fig.10, azimuth angle acceleration is also a pulse signal, probably achieve peak in $0.5 \mathrm{~s}$, and then quickly drop to zero. In general, peak increases with the increase of height.

Force generates from the contact of mirror and support, it reflects the amount of impact force, as shown in Fig.11.

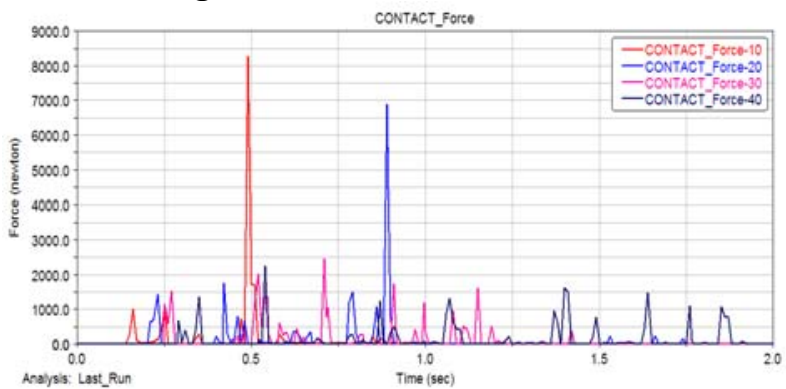

Fig.11 Contact force of reflector

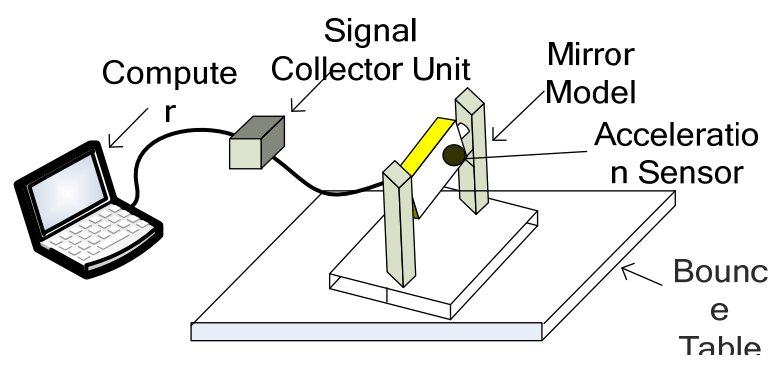

Fig.12 Experimental system

\section{Experiments}

\subsection{Experimental System.}

In order to study the effect of vibration on sight's structures, the paper sets up a corresponding experimental system to explore the influence of vibration on the mirror. The whole experimental system is shown in Fig.12. It contains vibration system and signal collect system. Main experimental equipments consist of mirror model, bounce table, acceleration sensor, signal collector unit and signal conditioner, computer, and corresponding software system [12].

As shown in Fig.13 and Fig.14, the Mirror model suspends on the support through two bearing retainer. Outline of the mirror is similar to a rectangle, $255 \mathrm{~mm}$ long, $165 \mathrm{~mm}$ wide and $20.75 \mathrm{~mm}$ thick. Mirror material is Titanium Alloy, and the surface is covered with silver lamina, the density is $4.45 \times 10^{3} \mathrm{~kg} / \mathrm{m}^{3}$, weight is $15.74 \mathrm{~N}$, volume is $360395.2 \mathrm{~mm}^{3}$, turning radius is $87.92 \mathrm{~mm}$, the principal moments of inertia expressed as $\mathrm{I}_{1}=12355.69 \mathrm{~N} \cdot \mathrm{mm}, \mathrm{I}_{2}=9275.92 \mathrm{~N} \cdot \mathrm{mm}, \mathrm{I}_{3}=3182.29 \mathrm{~N} \cdot \mathrm{mm}$.

As shown in Fig.15, the acceleration sensor named IEPE three directions piezoelectric acceleration sensor. It is the most popular vibration sensor, which has good dynamic property and powerful overload resistance. The property parameters are shown in Table 1. 


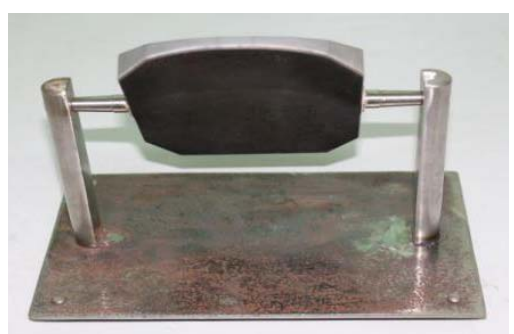

Fig.13 Entity of reflector model

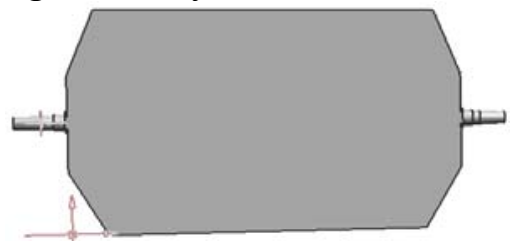

Fig.14 Model of the reflector

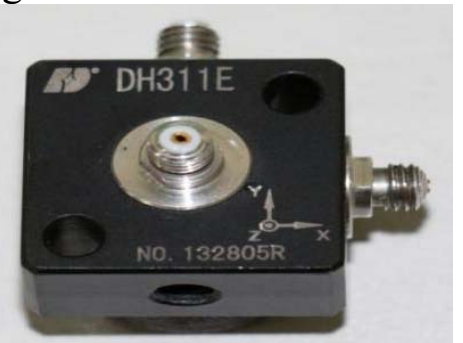

Fig.15 IEPE three directions piezoelectric acceleration sensor

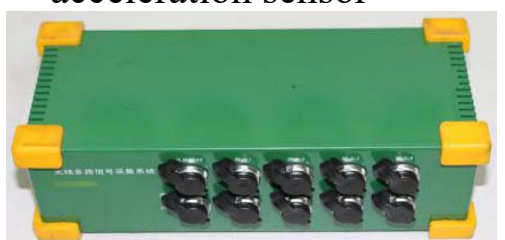

Fig.16 DH5910 solid type dynamic data recorder

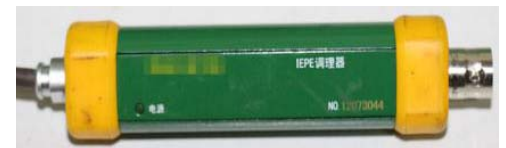

Fig.17 Signal conditioner/amplifier

\begin{tabular}{|c|c|c|c|}
\hline \multicolumn{3}{|c|}{ IEPE Three Directions Piezoelectric } \\
Acceleration Sensor
\end{tabular}

Table 1 Parameters of IEPE sensor

As shown in Fig.16, DH5910 solid type dynamic data recorder has 8 channels and $100 \mathrm{kHz} / \mathrm{CH}$ synchronous sampling rate. Its boundary dimension is $180 \mathrm{~mm} \times 80 \mathrm{~mm} \times 60 \mathrm{~mm}$.

Fig. 17 shows the signal conditioner in experiment, it can translate and amplify acceleration signal into voltage signal, then convey to the DH5910 recorder.

\subsection{Experiment Process.}

Vibration shock experiment condition is shown in Table 2,and the experimental results are shown in Fig.18 and Fig.19. 
Table 2 Vibration shock condition

\begin{tabular}{|c|c|c|c|}
\hline $\begin{array}{c}\text { Accelerati } \\
\text { on peak } \\
/ \mathrm{m} \cdot \mathrm{s}^{-2}\end{array}$ & $\begin{array}{c}\text { Experi } \\
\text { ment }\end{array}$ & $\begin{array}{c}\text { Simulat } \\
\text { ion }\end{array}$ & $\begin{array}{c}\text { Relative } \\
\text { error }\end{array}$ \\
\hline $\mathrm{X}$ & 949.66 & 830.56 & $12.54 \%$ \\
\hline $\mathrm{Y}$ & 423.18 & 398.12 & $5.91 \%$ \\
\hline $\mathrm{Z}$ & 635.10 & 678.39 & $6.77 \%$ \\
\hline
\end{tabular}

Table 3 Contrast of acceleration peak

\begin{tabular}{|c|c|c|c|c|}
\hline $\begin{array}{l}\text { Acceler } \\
\text { ation } / g\end{array}$ & $\begin{array}{c}\text { Tim } \\
\mathrm{e}\end{array}$ & $\begin{array}{c}\text { Freque } \\
\text { ncy }\end{array}$ & $\begin{array}{l}\text { Temper } \\
\text { ature }\end{array}$ & $\begin{array}{l}\text { Humi } \\
\text { dity }\end{array}$ \\
\hline 10 & \multirow{4}{*}{$\begin{array}{l}1-3 \\
\mathrm{~ms}\end{array}$} & 9 & \multirow{4}{*}{$15-35^{\circ} \mathrm{C}$} & \multirow{4}{*}{$\begin{array}{c}20-80 \\
\%\end{array}$} \\
\hline 20 & & 7 & & \\
\hline 30 & & 5 & & \\
\hline 40 & & 3 & & \\
\hline
\end{tabular}

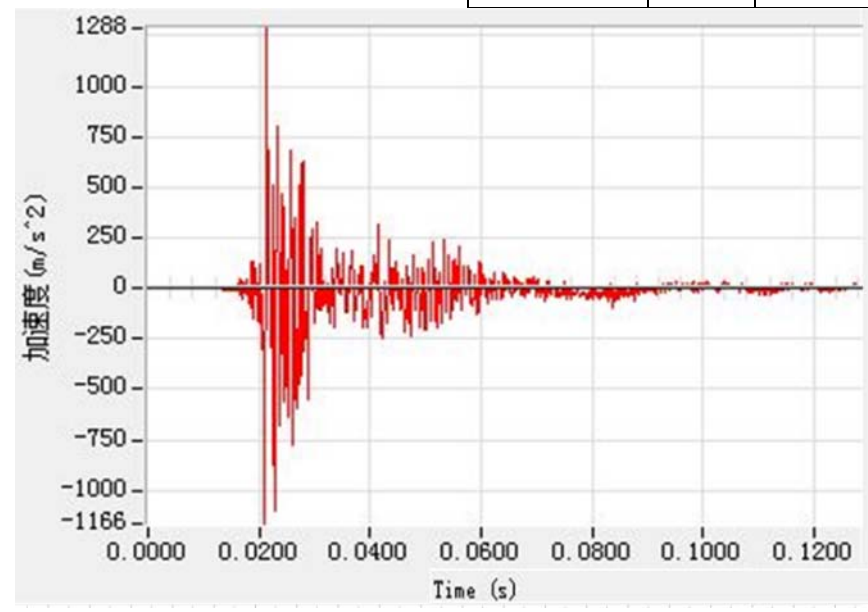

Fig.18 Pitch acceleration

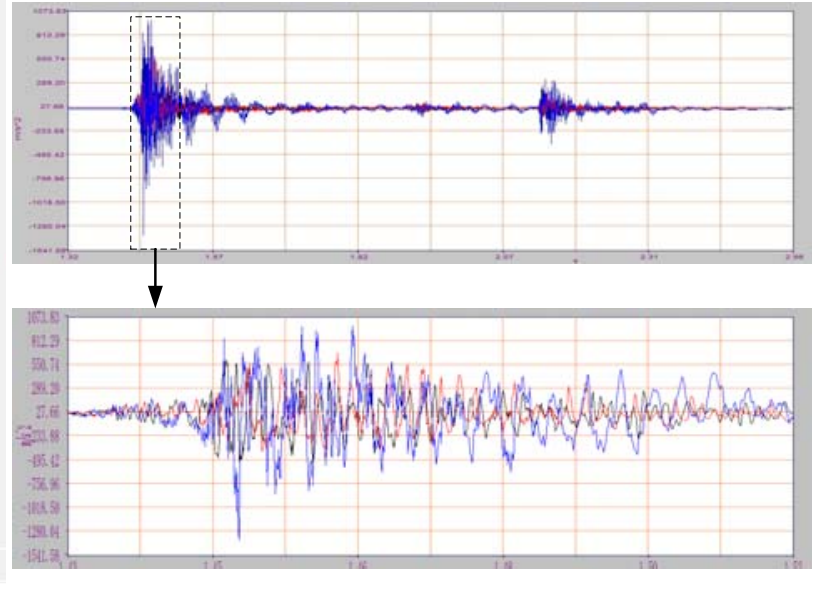

Fig.19 Acceleration of three directions

From the contrast of experiment and simulation, we can reach a conclusion that the model fits the actual situation, which provides an important reference for the design and production of this type of product.

\section{Conclusion}

This paper uses the ADAMS to establish a dynamic model of a certain type of vehicle-mounted optics image stabilization system and makes simulation analysis on aiming mirror. Conclusions are as follow:

(1) The paper builds the model of vehicle-mounted optics image stabilization system and makes simulation analysis on tank drop; it provides an effective means to study the photoelectric equipment and has great value for vehicle-mounted optics image stabilization system structure design, so as to improve tank's environmental adaptability.

(2) The experimental results agreed with the simulations, which confirms the correctness of the model and provides an important reference for the design of product.

(3) By making simulation analysis of the aiming mirror drops from different height. We found that response increases with the increase of height. Otherwise, the pitch angle changes greater than the azimuth angle. Thus designer could concentrate on the pitch control at early, to insure the product with high quality.

\section{References}

[1] Z. X. Guo, Use of 1A40-1 comprehensive aiming mirror of T-72C tank, Weapon System, 5, 1997, pp23-28. 
[2] D. S. Steinberg, Vibration Analysis of Electronic Equipment, John Wily \& Son, 1988.

[3] H. Wang, Drop response analysis of LCD panel, Science and Technology Innovation Herald, 27, 2012, pp16-18.

[4] Q. Li, X.F. Zhang, X.P. Yan, G.F. Cheng, Simulation of fault of tank's sighting system due to fretting of optical parts, Science and Technology Herald, 31,2013, pp 22-25.

[5] C. Z. Wang, X.L. Li, Q.L. Wang, C.L. Zhang, J.F. Zhu, Transition course model of gunner sight's indexes for tank firing simulator, Fire Control \& Command Control,35,2010, pp131-133.

[6] Y.H. Zhang, S. Li, G.Y. Liu, J. Chen, H.B. Li, Dropping simulation and selecting of cushion packaging methods for a infrared lens, Journal of Vibration and Shock, 33, 2014, pp133-137.

[7] H.H. Chen, X.Q. Wang, Technical comparison between upper reflector stabilized sight and lower reflector stabilized sight, Acta Armamentarii, 3, 1999, pp49-52.

[8] X. Chen, Q.Y. Zhang, F.Q. Zhao, Demonstration of image-stable principle of down-reflection image-stable vehicle-mounted optics image stabilization system, Gun Launch \& Control Journal, 2003,pp112-115.

[9] J.F. Zhu, B.J. Zhao, Q.Z. Wang, Modern tank fire control system, National Defense Industry Press, 2003.

[10] Y.M. Zhang, Mechanical vibration, Tsinghua University Press, 2007.

[11] F.H. Chen, ADAMS 2012 from introduction to the master of virtual prototype technology, Tsinghua University Press, 2013.

[12] S.L. Wu, Practical technology of vibration experiment, Weapon Industry Press, 1993. 